\title{
A Case of Duodenal Obstruction and Pancreatitis Due to Intragastric Balloon
}

\author{
Alaattin Öztürk ${ }^{1}$, Yunus Yavuz², Talha Atalay ${ }^{1}$ \\ ${ }^{1}$ Department of General Surgery, Fatih University Faculty of Medicine, İstanbul, Turkey \\ ${ }^{2}$ Department of General Surgery, American Hospital, İstanbul, Turkey
}

Background: Intragastric balloons have several advantages such as easy placement and low complication rates over other bariatric procedures. It is very rare for intragastric balloons to dislodge and give rise to pancreatitis. In this article, we present a case of duodenal obstruction caused by a gastric balloon leading to pancreatitis.

Case Report: A 38-year-old obese female patient had undergone intragastric implantation one month before admission. The patient was admitted to our hospital because of sudden onset of abdominal pain. On the abdominal ultrasonography and tomography, edematous pancreatitis and cholelithiasis were observed. The patient was given medical treatment for pancreatitis. Abdominal ultrasonography was repeated on the next day, and a distended gallbladder was revealed. Thus, the patient was operated on with the pre-diagnosis of acute cholecystitis and biliary pancreatitis. Laparoscopic cholecystectomy was performed. During the operation, a hard and trapped object was determined in the second part of the duodenal lumen. The patient was reevaluated on the second postoperative day as her pain had increased. On direct abdominal X-ray and computed tomography scan, the tubular part of the gastric balloon was found to be stuck in the duodenum. A gastroscopy was performed, but the balloon could not be removed. Therefore, an immediate laparotomy was performed, and the balloon was removed via gastrotomy.

Conclusion: Although intragastric balloons are designed to reduce the risk of displacement, all unexpected patient complaints should lead to a thorough examination of the position and status of the balloon.

Keywords: Duodenal obstruction, gastric balloon, pancreatitis
Morbid obesity has become a severe health problem, especially in Western countries. The prevalence of the disease has been gradually increasing over recent years. Obesity is treated using several methods, such as dietary programs, exercising, and medical therapy, which may involve implanting an intragastric balloon or surgery (1). Depending on the medical condition and socio-economic status of the patient, one or a combination of these methods can be employed. Each method has its pros and cons. Implanting a balloon device in the stomach helps with weight loss by generating a sense of fullness and reduces the volume available for food (2). However, implanting an intragastric balloon has some complications (3) and these should be kept in mind when evaluating patients with an intragastric balloon. The current report presents a case in which the tubular part of an intragastric balloon partially obstructed the duodenum and caused pancreatitis.

\section{CASE PRESENTATION}

A 38-year-old obese female patient (Body Mass Index $=48$ ), who was already under treatment for obesity (diet and exercise) and had not accepted bariatric surgery because of concomitant pulmonary disease, had undergone intragastric 


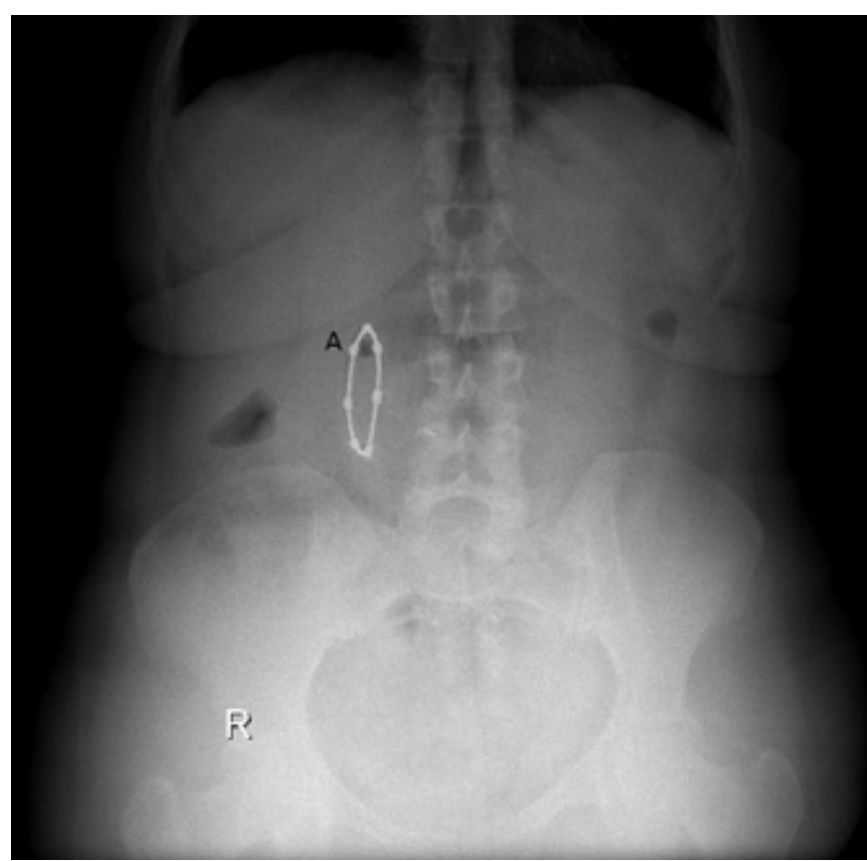

FIG. 1. The tubular part of the balloon is seen in the duodenum on the abdomen X-ray. The tubular part of the balloon.

balloon (Spatz Adjustable Balloon System ${ }^{\mathrm{TM}}$, Spatz FGIA, Inc., NY, USA) implantation in another hospital one month prior to admission. The patient was admitted to our hospital because of sudden onset of abdominal pain with duration of one day and she had been fasting for about 10 hours. The patient had tenderness around the umbilicus. The blood analysis was as follows: leucocyte: $13100 / \mathrm{mm}^{3}$, blood glucose: 67 $\mathrm{mg} / \mathrm{dL}$, amylase: $3602 \mathrm{U} / \mathrm{L}$, lipase: $38529 \mathrm{U} / \mathrm{L} \mathrm{Ca:} 9.2 \mathrm{mg} / \mathrm{dL}$ and lactate dehydrogenase: $964 \mathrm{U} / \mathrm{L}$; cholesterol, triglyceride, bilirubin and alkaline phosphatase were normal. On the patient's abdominal ultrasonography, edematous pancreatitis and cholelithiasis were observed. CT revealed a small fluid collection around the pancreas and intragastric balloon, and no dilatation or stone in the biliary tree. In addition, magnetic resonance cholangiography showed peripancreatic flood collection and normal diameter of the common bile duct and Wirsung's canal. The patient was hospitalized, and medical treatment for pancreatitis was initiated. Abdominal ultrasonography, repeated the next day because of increased complaints of pain, showed a distended gallbladder. Thus, the patient was operated on with the pre-diagnosis of acute cholecystitis and biliary pancreatitis. Laparoscopic cholecystectomy was performed, but no sign of acute cholecystitis was detected macroscopically. During the operation, a hard and trapped object (the tubular part of the gastric balloon) was felt in the second part of the duodenum. We did not perform any other intervention because we did not suspect any complication due to the balloon.

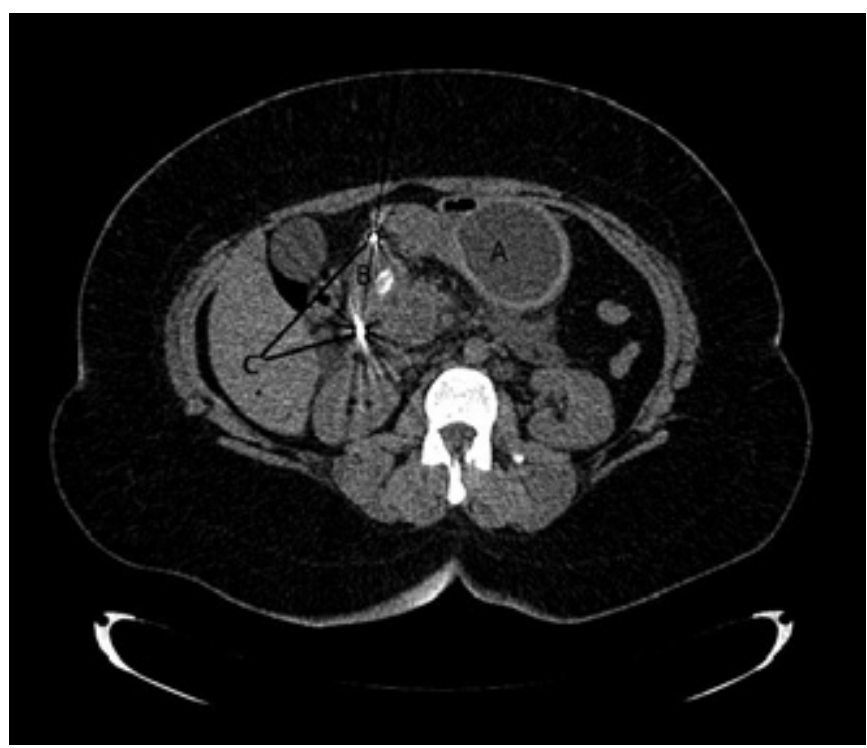

FIG. 2. The balloon and its tubular part are seen on computed tomography. Intragastric balloon (a). Duodenum (b). The tubular part of the balloon (c).

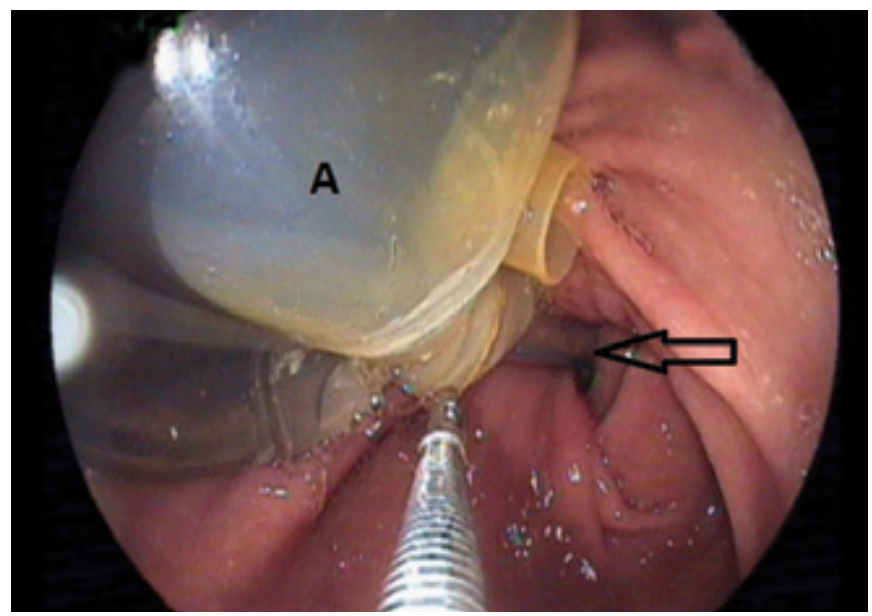

FIG. 3. The stuck balloon in the duodenum on gastroscopy. Intragastric balloon, Arrow: The tubular part of balloon.

The patient was reevaluated on the second postoperative day as her pain had increased, because of the possibility of development of another complication. On direct abdominal Xray and computed tomography scan, the tubular part of gastric balloon was found to be stuck in the duodenum (Figure 1 and 2), and we concluded that the complaints were due to the stuck tubular part of the balloon. A gastroscopy was performed but the balloon could not be removed (Figure 3). Therefore, an immediate laparotomy was performed, and the balloon was removed via gastrotomy (Figure 4). In the postoperative period, C-reactive protein (CRP), amylase and lipase values declined (from 300 to $40 \mathrm{mg} / \mathrm{dL}$, from 3602 to $41 \mathrm{U} / \mathrm{L}$, and from 38,529 to $195 \mathrm{U} / \mathrm{L}$, respectively) and the pain decreased. Therefore, 


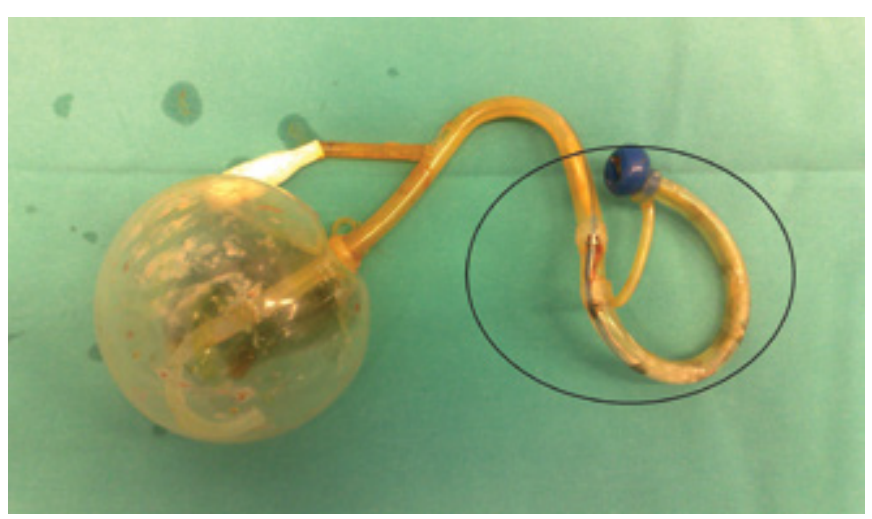

FIG. 4. The balloon after removal. Ring: The stuck part of balloon.

we concluded that pancreatitis was caused by compression of the tubular part of the balloon to the papilla of duodenum. Informed consent was obtained from the patient for this case report.

\section{DISCUSSION}

There are many therapeutic options for morbid obesity, such as diet, exercise, behavioral therapy, drug therapy, surgical treatment, and the placement of a balloon in the stomach. Despite the use of balloon placement for weight loss since 1985 (4), the clinical efficacy and safety of the method have been evaluated (3-5). Balloon placement is less invasive when compared to surgery and more effective when compared to medical treatment (3-6); for these reasons, it is a commonly performed procedure. Balloon therapy is a temporary and easy therapeutic option for obese patients who do not want obesity surgery $(2,3)$. However, patients may regain weight if they do not eventually undergo surgery (7).

The placement of intragastric balloons may have complications such as gastric perforation, bowel obstruction, gastroduodenitis, exacerbation of the ulcer, and worsening reflux esophagitis $(3,5,8)$. Genco et al. (5) determined that the complication rate related to balloon placement was $2.8 \%$ in a series of 2515 patients. Although esophagitis and gastric outlet obstruction are commonly seen complications, pancreatitis is not. One case report stated that migration of the balloon to the small intestine can cause pancreatitis (9), while another (10) described the pressure of the balloon on the pancreas as a cause of pancreatitis. In both cases, removal of the balloon led to recovery. These reports demonstrated that pancreatitis was a rare complication of intragastric balloon placement.

In the present case, the patient's abdominal pain and symptoms of pancreatitis were not alleviated following the cholecystectomy. It was only after removal of the balloon that the patient's symptoms, examination findings, amylase values, and CRP values were seen to improve rapidly. The patient's rapid improvement indicated that the compression of the pancreas by the tubular part of the balloon lodged in the duodenum was the actual cause of the pancreatitis.

When free gastric balloons deflate spontaneously, they can move into the small intestine and cause intestinal obstruction (11). More durable balloons have been produced in response to cases of bursting. The inflation-deflation of the new balloon types can be controlled using a handle under the skin. The risk of both deflation and displacement is lower with these than with free balloons, and the complications seen with the use of free gastric balloons have not been observed with the new types (12). Another balloon has been introduced with a feature that is supposed to prevent migration (Figure 4). This type of balloon was implanted in our patient; however, this feature did not prevent migration of the balloon. In the present case, migration of the tubular part of the balloon into the duodenum led to the local irritation and pancreatitis.

The placement of an intragastric balloon is a temporary procedure designed to help patients lose weight (6). Balloons should be removed at the end of a period lasting no longer than six months. If necessary, they can be replaced with a new one. Balloons remaining in the stomach for more than six months increase the possibility of complications (11). In the present case, however, the patient developed complications after only one month of placement.

The first treatment method in cases of gastric balloon complications should be the removal of the balloon that may have migrated to the duodenum and obstructed the pylorus by gastroscopy $(5,10)$. If this process is not successful, or if the balloon causes an obstruction further down the small intestine, laparotomy or laparoscopic surgery should be performed (13). In our case, initial treatment consisted of gastroscopy, followed by a laparotomy when the gastroscopy was unsuccessful.

In this report, we present a case in which the tubular part of a gastric balloon migrated into the duodenum and caused pancreatitis due to occlusion of the papilla. The presence of obesity and cholelithiasis did not adequately explain the cause of the patient's pancreatitis. Despite the cholecystectomy and medical treatment given, CRP levels remained high and the patient's complaints failed to subside. After removing the balloon from the duodenum, the patient's symptoms and examination findings rapidly improved. The patient's rapid improvement indicated that the actual cause of the pancreatitis was the occlusion of the papilla by a part of the balloon trapped in the duodenum. In this case, we did not realize that the tubular part of the gastric balloon migrating to duodenum had led to complications in the first CT, because we were focused on cholecystitis and biliary pancreatitis. Although intragastric balloons 
are designed to reduce the risk of displacement, all unexpected patient complaints should lead to a thorough examination of the position and status of the balloon.

Ethics Committee Approval: N/A.

Informed Consent: Written informed consent was obtained from the patient.

Peer-review: Externally peer-reviewed.

Author contributions: Concept - A.Ö., Y.Y.; Design - A.Ö.; Supervision - Y.Y.; Resource - A.Ö., T.A.; Materials - A.Ö.; Data Collection \&/or Processing - A.Ö., T.A.; Analysis \&/or Interpretation - A.Ö., Y.Y; Literature Search - A.Ö., T.A.; Writing - A.Ö., T.A.; Critical Reviews - A.Ö., Y.Y.

Conflict of Interest: No conflict of interest was declared by the authors.

Financial Disclosure: The authors declared that this study has received no financial support.

\section{REFERENCES}

1. National Institutes of Health [Internet]. Bethesda, USA. How Are Overweight and Obesity Treated? Available from: http:// www.nhlbi.nih.gov/health/health-topics/topics/obe/treatment. html

2. Peker Y, Coskun H, Bozkurt S, Cin N, Atak T, Genc H. Comparison of results of laparoscopic gastric banding and consecutive intragastric balloon application at 18 months: a clinical prospective study. J Laparoendosc Adv Surg Tech A 2011;21:471-5. [CrossRef]
3. Imaz I, Martínez-Cervell C, García-Alvarez EE, Sendra-Gutiérrez JM, González-Enríquez J. Safety and effectiveness of the intragastric balloon for obesity. A meta-analysis. Obes Surg 2008;18:841-6. [CrossRef]

4. Ramadan MEA, Abdel Hamid HK, Ramadan AR, Abdel Kader AR. Bioenterics Intragastric Balloon: Safety, Tolerance, and Efficacy of 6 months Balloon Treatment: Egyptian Experience with 50 patients. N Y Sci J 2014;7:6-9.

5. Genco A, Bruni T, Doldi SB, Forestieri P, Marino M, Busetto $\mathrm{L}$, at al. Bioenterics intragastric balloon: The Italian experience with 2515 patients. Obes Surg 2005;15:1161-4. [CrossRef]

6. Mathus-Vliegen EM. Intragastric balloon treatment for obesity: what does it really offer? Dig Dis 2008;26:40-4. [CrossRef]

7. Angrisani L, Lorenzo M, Borelli V, Giuffre M, Fonderico C, Capece G. Is bariatric surgery necessary after intragastric balloon treatment? Obes Surg 2006;16:1135-7. [CrossRef]

8. Sallet JA, Marchesini JB, Paiva DS, Komoto K, Pizani CE, Ribeiro ML, at al. Brazilian multicenter study of the intragastric balloon. Obes Surg 2004;14:991-8. [CrossRef]

9. Holland S, Bach D, Duff J. Balloon therapy for obesity-when the balloon bursts. J Can Assoc Radiol 1985;36:347-49.

10. Mohammed AE, Benmoua A. Acute pancreatitis complicating intragastric balloon insertion. Case Rep Gastroenterol 2008;2:291-5. [CrossRef]

11. Ozturk A, Akinci, OF, Kurt M. Small intestinal obstruction due to self-deflated free intragastric balloon. Surg Obes Relat Dis 2010;6:569-71. [CrossRef]

12. Gaggiotti G, Tack J, Garrido AB Jr, Palau M, Cappelluti G, Di Matteo F. Adjustable totally implantable intragastric prosthesis (ATIIP)- Endogast for treatment of morbid obesity: one-year follow-up of a multicenter prospective clinical survey. Obes Surg 2007;17:949-56. [CrossRef]

13. Vanden Eynden F, Urbain P. Small intestine gastric balloon impaction treated by laparoscopic surgery. Obes Surg 2001;11:646-8. [CrossRef] 